\title{
Too much of a good thing? Lecithin and mental health
}

Author: Ioannis Tsoukalas

Affiliation: Stockholm University, Stockholm, Sweden

\section{Abstract}

The present article is concerned with some aspects of lecithin metabolism and function as they pertain to mental health. Given that lecithin is a popular emulsifier in the food industry, as well as an active substance in many supplement formulations, its effects on mental health deserve special attention from a public health perspective. In this regard it is worrisome that a number of scientific studies, both old and new, have implicated the overconsumption of choline (a main ingredient of lecithin) in the causation of depression. The article discusses some of these concerns and proposes simple remedies.

Keywords: lecithin, emulsifier, choline, acetylcholine, mental health, depression, food industry, supplement industry, public health 
Lecithin is a versatile substance used in many foods, drugs and supplements, mostly as an emulsifier. ${ }^{1}$ Given its many applications and commercial popularity, it is important to look at some of its potential health effects, in particular its mental health effects. By extension, this article will also have a brief look into two related substances, namely choline and acetylcholine.

\section{Nature of lecithin}

Lecithin is the generic term used for a class of yellow-brownish fatty substances which, depending on the source of the lecithin in question, consist of varying proportions of phosphatidylcholine, phosphatidylethanolamine, phosphatidylinositol and phosphatidic acid. Lecithin is found naturally in many common foodstuffs - like, eggs, liver, soybeans, nuts and seeds - but is also produced industrially in large quantities (see Szuhaj, 1989; Smith \& HongShum, 2011; List, 2015; Shurtleff \& Aoyagi, 2016).

Lecithin is not an inert substance. It supplies the human body with a very important nutrient, namely choline. Choline has two main biological functions: it serves as a building block of cell membranes in the body and it is the precursor of acetylcholine. Acetylcholine is one of the main neurotransmitters of the central nervous system and plays a central role in cortical activation, behavioral inhibition, attention, memory and learning processes (Hasselmo, 2006; Kuo et al., 2007; Botly \& de Rosa, 2008). The cholinergic circuits of the brainstem are also responsible for the production and control of REM sleep and hence play a crucial role in the regulation of the sleep-wake cycle (Hobson 1999; Tsoukalas 2012). Acetylcholine is the exclusive neurotransmitter of the parasympathetic nervous system, the part of the autonomic nervous system that is responsible for digestion, rest, recuperation and reproduction (McCorry, 2007).

Humans attain most of their choline through their diet. Since it plays such important roles in the human body, its metabolism and circulation is tightly controlled. However, though the body has defense mechanisms against excess choline concentrations in the brain, these controls only function under physiological conditions and may be overrun by dietary loading or direct supplementation (Löffenholz et al., 1993; Löffelholz \& Klein, 2004). Hence, studies have found that feeding lecithin to animals or humans significantly elevates levels of blood choline, brain choline and acetylcholine (Hirsch \&Wurtman, 1978; Magil et al., 1981; Löffenholz et al., 1993; Wurtman et al, 2009). Further, even transient increases in brain choline concentration can have central cholinergic effects (parasympathetic stimulation) since choline is a powerful agonist at muscarinic and nicotinic receptors (Ulus et al., 1988). Interestingly, carbohydrate-rich foods seem to potentiate the synthesis of acetylcholine from choline (Klein et al., 2004). Given the neuroactive nature of choline, what are the consequences of consuming excessive amounts of lecithin?

\section{Choline is depressogenic}

What is most relevant for the purposes of this article is that lecithin may cause depression. This effect is mainly mediated by its high content of phosphatidylcholine, which facilitates the endogenous production of acetylcholine. There are several lines of evidence pointing in this direction as indicated below:

- Janowsky et al. (1974) were the first to point out the depressogenic properties of lecithin. Their theory came to be known as the acetylcholine theory of depression. Since then, their basic proposition has been corroborated by substantial evidence. This body of work, spanning over several decades, amounts to a complete research program with experimental studies, theoretical work and clinical interventions (Janowsky et al., 1994; van Enkhuizen et al., 2015). 
- Several other research groups have confirmed the relationship between choline and subdued mood and even proposed that it represents the endophenotype of clinical depression (Dagyté et al., 2011; Mineur et al., 2013; Higley \& Picciotto, 2014).

- A number of intervention studies with anticholinergic agents have led to the rapid relief or remission of depressive symptoms in both animals and humans (Janowsky, 2011; Hasselmann, 2014; Liu et al., 2016; Su et al., 2018).

- The relationship between brain choline and depression has also been demonstrated by a number of brain imaging studies (Yildiz-Yesiloglu \& Ankerst, 2006; Riley \& Renshaw, 2018).

Beside these points, there is a wealth of indirect evidence connecting choline to psychological functioning, including depression. Thus, for example, a number of studies have found lecithin (or choline) to be helpful in the treatment of mania, the psychological "opposite" of depression, as it has a mood lowering effect (Cohen et al., 1982; Wood \& Allison, 1982; Leiva, 1990; Stoll el al., 1996; Rao et al., 2015). Similarly, researchers have suspected for a long time that smoking may have an antidepressant effect and this has been explained by the action of nicotine on nicotinic acetylcholine receptors (nAChRs); nicotine binds to and desensitizes these receptors, thus making them less sensitive to the workings of acetylcholine (Benowitz, 2010; Mineur \& Picciotto, 2010). Further, within sleep medicine, it is wellestablished that a dysregulation of the sleep-wake cycle leading to a preponderance of REM sleep (which is driven by acetylcholine) has a clearly depressogenic effect (Vogel et al., 1980; Hobson 1999; Riemann et al., 2001).

\section{Wide ramifications}

These findings, which are not widely known, have important implications for public health. This is so because lecithin is added as an emulsifier to a large number of manufactured foodstuffs. Although it falls outside the scope of the present article to extensively review them, it suffices to say that the use of lecithin spans almost the whole gamut of ready-made foodstuffs and includes such major categories as: condiments (e.g., sauces, dips), dairy products (e.g., compound butter, ice-cream), baked goods (e.g., bread), confectionaries (e.g., cookies, pastries, puddings, chocolate, candies) and drinks (e.g., shakes, smoothies). Recently its use has expanded to such a degree that it has also found its way into such "unexpected" products as chewing gum and tea bags (see Szuhaj, 1989; Smith \& Hong-Shum, 2011; List, 2015; Shurtleff \& Aoyagi, 2016).

Similar practices exist in other areas as well. The supplement industry, for instance, regularly uses lecithin in its various products. Lecithin is here used in a dual sense: both as an active substance (e.g., for cholesterol or liver problems), in which case the exact amounts are declared on the nutrition facts label, or as an excipient (i.e., emulsifier or vector), in which case the exact amounts are usually not declared. Sometimes the amounts involved are considerable and far in excess of what would be absorbed from a natural diet (see Szuhaj, 1989; Smith \& Hong-Shum, 2011; List, 2015; Shurtleff \& Aoyagi, 2016).

It is not difficult to see the dangers of this situation. If we add up the various lecithin sources the aggregate level of choline intake may become excessive and inadvertently push vulnerable individuals into depression. The widespread use of lecithin may thus effectively lead to a collective lowering of the threshold for clinical depression. ${ }^{2}$ This situation is reminiscent to the one produced by the "added sugar" practice, the adding of sugar or starch in order to increase a products palatability and/or make it more low-fat, a practice that became common in the last decades of the previous century and that is, in many ways, still current. We now know 
that this practice was a contributing factor to the increased incidence of both diabetes and obesity around the world (Malik et al., 2010; Morenga et al., 2012; Lobstein, 2014).

I believe that the above-mentioned practices, which affect the lives of millions of people around the world, need to be carefully reconsidered in light of the findings of the acetylcholine theory of depression discussed above. This reconsideration is more urgent than ever now that depression has taken on the character of a global epidemic (Murray \& Lopez, 1996; Kessler et al., 2006) and the need for new therapeutic approaches has become apparent. ${ }^{3}$

\section{Simple remedies}

So, what should be done? To begin with, we should not throw out the baby with the bath water. As mentioned above choline is a natural substance found in many foodstuffs and also an essential nutrient for the human body. ${ }^{4}$ There are even studies showing that segments of the population are deficient in this important nutrient (Zeisel \& da Costa, 2009) and that choline may be protective against anxiety (Bjelland et al., 2009). ${ }^{5}$ There are, fortunately, ways to get out of this seeming “double-bind”. Below I list two such remedies, but others could easily be conceived of.

The first is the realization that knowledge is a "game changer". Presently, the exact amount of lecithin is not listed in the ingredients list or nutrition facts label of most products. Thus, consumers today do not know how much lecithin they are ingesting (and, as mentioned above, lecithin is ubiquitous). Some products may contain only tiny amounts of lecithin in which case their consumption would have negligible effects on mental health, while other products may contain larger amounts of lecithin in which case their consumption could have noticeable effects on mental health. This situation could easily be rectified if producers were to disclose the exact amount of lecithin contained in their products, as has been done, for example, in the case of salt $(\mathrm{NaCl})$. Another possibility is to categorically state whether lecithin is a major ingredient or a minor ingredient of a given product, a practice used in the USA (the "less than 2\%" entry in some ingredients lists; the cut-off level could of course be set differently); even though not as satisfactory as a full disclosure of content, it is a means to the same end. In any case, by giving this vital information to consumers, they will be better able to make well-informed choices, something which will, in the long run if not immediately, have a positive impact on their health.

Another approach is to acknowledge that there are great individual differences in how people react to dietary or supplemental choline. These differences may even be related to personality types (Tops et al., 2010; Pitchers et al., 2017). For instance, there is preliminary evidence that points to a preponderance of cholinergic neurotransmission in introversion (Laney, 2002; Xu et al., 2005) and a deficit of cholinergic neurotransmission in ADHD (English et al., 2009). Therefore, both the lay audience and the expert community need to be sensitized to the importance of these individual differences as they relate to the availability of dietary or supplemental lecithin/choline. If such health awareness can be raised, for example by information campaigns or warning labels, then we can both "eat our cake and have it"; those who are sensitive to the workings of choline can avoid it, those who need more can increase consumption of it, and those who are not sensitive can continue to enjoy their favorite products in either case.

\section{Conclusion}

In the present article, I have tried to raise awareness of a potentially troublesome situation, namely the fact that lecithin, a potentially depressogenic substance, is widely used in the food and supplement industries as an excipient or active ingredient. In closing, however, I want to qualify my statement lest it appear too monolithic. To begin with, I am not claiming that lecithin, or its derivatives, unequivocally causes depression. Depression is a multifactorial 
disorder with many factors - nutritional, genetic, social - contributing to its emergence and maintenance. Further, there are several different types of depression - unipolar, bipolar, melancholic - each with its particular etiology and course of treatment. And, as already mentioned, there are large individual differences in people's susceptibility to depression and its clinical manifestation. Therefore, the cost-benefit ratio of any single course of action (for example choosing to consume a given dietary substance) vis-à-vis depression cannot be given in advance but needs to be carefully considered on a case-to-case basis. Still, for people vulnerable to depression, caution is advised, as overconsumption of lecithin may pose a threat. However, since such people are numerous - probably numbering in the millions - this also constitutes a threat to public health. The degree of threat is of course an empirical question. There is, hence, a need to investigate the matter further in light of the present hypothesis and to raise awareness of these risks among the public and policy makers.

\section{References}

Aznar, S., \& Knudsen, G. M. (2011). Depression and Alzheimer's disease: is stress the initiating factor in a common neuropathological cascade? Journal of Alzheimer's Disease, 23 (2): 177193.

Benowitz, N. L. (2010). Nicotine addiction. The New England Journal of Medicine, 362 (24): 2295-2303.

Bjelland, I., Tell, G. S., Vollset, S. E., Konstantinova, S., \& Ueland, P. M. (2009). Choline in anxiety and depression: the Hordaland Health Study. American Journal of Clinical Nutrition, 90 (4): 1056-1060.

Botly, L. C., de Rosa, E. (2008). A cross-species investigation of acetylcholine, attention, and feature binding. Psychological Science, 19 (11): 1185-1193.

Cipriani, A., Zhou, X., Del Giovane, C., Hetrick, S. E., Qin, B., Whittington, C., Coghill, D., Zhang, Y., Hazell, P., Leucht, S., Cuijpers, P., Pu, J., Cohen, D., Ravindran, A. V., Liu, Y., Michael, K. D., Yang, L., Liu, L., \& Xie, P. (2016). Comparative efficacy and tolerability of antidepressants for major depressive disorder in children and adolescents: a network metaanalysis. Lancet, 388 (10047): 881-890.

Cipriani A., Furukawa, T. A., Salanti, G., Chaimani, A., Atkinson, L. Z., Ogawa, Y., Leucht, S., Ruhe, H. G., Turner, E. H., Higgins, J. P. T., Egger, M., Takeshima, N., Hayasaka, Y., Imai, H., Shinohara, K., Tajika, A., Ioannidis, J. P.A., \& Geddes, J. R. (2018). Comparative efficacy and acceptability of 21 antidepressant drugs for the acute treatment of adults with major depressive disorder: a systematic review and network meta-analysis. Lancet, 391 (10128): 1357-1366.

Cohen, B. M., Lipinski, J. F. \& Altesman, R. I. (1982). Lecithin in the treatment of mania: double-blind, placebo-controlled trials. The American Journal of Psychiatry, 139 (9): 11621164.

Dagyte, G., Den Boer, J.A, \& Trentani, A. (2011). The cholinergic system and depression. Behavioural Brain Research, 221 (2):574-582.

English, B. A., Hahn, M. K., Gizer, I. R., Mazei-Robison, M., Steele, A., Kurnik, D. M., Stein, M. A., Waldman, I. D., \& Blakely, R. D. (2009). Choline transporter gene variation is associated with attention-deficit hyperactivity disorder. Journal of Neurodevelopmental Disorders, 1(4): 252-263.

Fournier, J. C., DeRubeis, R. J., Hollon, S. D., Dimidjian, S., Amsterdam, J. D., Shelton, R. C., \& Fawcett, J. (2010). Antidepressant drug effects and depression severity: a patient-level meta-analysis. JAMA, 303 (1): 47-53.

Greenberg, G. (2010). Manufacturing Depression. The Secret History of a Modern Disease. New York: Simon \& Schuster. 
Hasselmann, H. (2014). Scopolamine and depression: a role for muscarinic antagonism? CNS \& Neurological Disorders Drug Targets, 13 (4): 673-683.

Hasselmo, M. (2006). The role of acetylcholine in learning and memory. Current Opinion in Neurobiology, 16 (6): 710-715.

Higley, M. J., \& Picciotto, M. R. (2014). Neuromodulation by acetylcholine: examples from schizophrenia and depression. Current Opinion in Neurobiology, 29: 88-95.

Hirsch, M. J., \& Wurtman, R.J. (1978). Lecithin consumption increases acetylcholine concentrations in rat brain and adrenal gland. Science, 202 (4364): 223-225.

Hobson, A. J. (1999). Dreaming as Delirium: How the Brain Goes Out of its Mind. Cambridge, MA: MIT Press.

Janowsky, D. S., el-Yousef, M. K, \& Davis, J. M. (1974). Acetylcholine and depression. Psychosomatic Medicine, 36 (3): 248-257.

Janowsky, D. S., Overstreet, D. H., Nurnberger, J. I. Jr. (1994). Is cholinergic sensitivity a genetic marker for the affective disorders? American Journal of Medical Genetics, 54 (4): 335-344.

Janowsky, D. S. (2011). Serendipity strikes again: scopolamine as an antidepressant agent in bipolar depressed patients. Current Psychiatry Reports, 13 (6): 443-445.

Kessler, R. C., Akiskal, H. S., Ames, M., Birnbaum, H., Greenberg. P., Hirschfeld, R. M., Jin, R., Merikangas, K. R., Simon, G. E., \& Wang, P. S. (2006). Prevalence and effects of mood disorders on work performance in a nationally representative sample of U.S. workers. The American Journal of Psychiatry, 163 (9): 1561-1568.

Kirsch, I., Deacon, B. J., Huedo-Medina, T. B., Scoboria, A., Moore, T. J., Johnson, B. T. (2008). Initial Severity and Antidepressant Benefits: A Meta-Analysis of Data Submitted to the Food and Drug Administration. PLoS Medicine, 5 (2): e45.

Kirsch, I. (2010). The Emperor's New Drugs. Exploding the Antidepressant Myth. New York: Basic Books.

Klein, J., Buchholzer, M. L., Kopf, S., \& Löffelholz, K. (2004). Conditions for a precursor control of acetylcholine release in mouse hippocampus. In I. Silman, H. Soreq, L. Anglister, D. Michaelson \& A. Fisher (eds.) Cholinergic Mechanisms. Function and Dysfunction. London: Taylor \& Francis.

Kuo, M. F., Grosch, J., Fregni, F., Paulus, W., \& Nitsche, M. A. (2007). Focusing effect of acetylcholine on neuroplasticity in the human motor cortex. The Journal of Neuroscience, 27 (52): 14442-14447.

Kulaksizoglu, I. B. (2007). Mood and anxiety disorders in patients with myasthenia gravis: aetiology, diagnosis and treatment. CNS Drugs, 21 (6): 473-481.

Laney, M. O. (2002). The Introvert Advantage: How Quiet People Can Thrive in an Extrovert World. New York: Workman Publishing Company.

Leiva, D. B. (1990). The neurochemistry of mania: a hypothesis of etiology and a rationale for treatment. Progress in Neuro-Psychopharmacology and Biological Psychiatry, 14 (3): 423429.

List, G. R. (2015). Soybean lecithin: food, industrial uses, and other applications. In U. A. Moghis and X. Xuebing (eds.) Polar Lipids: Biology, Chemistry, and Technology (pp. 133). Urbana, Illinois: Academic Press and AOCS Press.

Liu, J., Dupree, J. L., Garcia, M., Frawley, R., Sikder, T., Naik, P., \& Cassaccia, P. (2016). Clemastine enhances myelination in the prefrontal cortex and rescues behavioral changes in socially isolated mice. The Journal of Neuroscience, 36 (3): 957-962.

Lobstein, T. (2014). Reducing consumption of sugar-sweetened beverages to reduce the risk of childhood overweight and obesity. World Health Organization, e-Library of Evidence for Nutrition Actions (eLENA). Last accessed on 2018 Oct 30, found at http://www.who.int/elena/titles/commentary/ssbs_childhood_obesity/en/]. 
Löffelholz, K., \& Klein, J., \& Köppen, A. (1993). Choline, a precursor of acetylcholine and phospholipids in the brain. In A. C. Cuello (ed.) Cholinergic Function and Dysfunction. London: Elsevier.

Löffelholz, K., \& Klein, J. (2004). How is the brain protected against excess choline concentrations? In I. Silman, H. Soreq, L. Anglister, D. Michaelson \& A. Fisher (eds.) Cholinergic Mechanisms. Function and Dysfunction. London: Taylor \& Francis.

Magil, S. G., Zeisel, S. H., \& Wurtman, R. J. (1981). Effects of ingesting soy or egg lecithins on serum choline, brain choline and brain acetylcholine. The Journal of Nutrition, 111 (1): 166-170.

Malik, V. S., Popkin, B. M., Bray, G. A., Després, J. P., \& Hu, F. B. (2010). Sugar-sweetened beverages, obesity, type 2 diabetes mellitus, and cardiovascular disease risk. Circulation, 121 (11): 1356-1364.

McCorry, L. K. (2007). Physiology of the autonomic nervous system. American Journal of Pharmaceutical Education, 71 (4): 78. Mineur, Y. S., \& Picciotto, M. R. (2010). Nicotine receptors and depression: revisiting and revising the cholinergic hypothesis. Trends in Pharmacological Sciences, 31 (12): 580-586.

Mineur, Y. S., Obayemi, A., Wigestrand, M. B., Fote, G. M., Calarco, C. A., Li, A. M., \& Picciotto, M. R. (2013). Cholinergic signaling in the hippocampus regulates social stress resilience and anxiety- and depression-like behavior. Proceedings of the National Academy of Sciences of the U.S.A., 110 (9): 3573-3578.

Morenga, L. T., Mallard, S., \& Mann J. (2012). Dietary sugars and body weight: systematic review and meta-analyses of randomised controlled trials and cohort studies. BMJ: 346:e7492.

Murray, C. J., \& Lopez, A. D. (1996). The Global Burden of Disease: A Comprehensive Assessment of Mortality and Disability from Diseases, Injuries and Risk Factors in 1990 and Projected to 2020. Geneva, Switzerland: World Health Organization. [Last accessed on 2018 Aug 25, found at http://www.who.int/iris/handle/10665/41864].

Pitchers, K. K., Kane, L. F., Kim, Y., Robinson, T. E., \& Sarter, M. (2017). 'Hot' vs. 'cold' behavioural-cognitive styles: motivational-dopaminergic vs. cognitive-cholinergic processing of a Pavlovian cocaine cue in sign- and goal-tracking rats. European Journal of Neuroscience, 46 (11): 2768-2781.

Riemann, D., Berger, M., \& Voderholzer, U. (2001). Sleep and depression - results from psychobiological studies: an overview. Biological Psychology, 57 (1-3): 67-103.

Riley, C. A., \& Renshaw, P. F. (2018). Brain choline in major depression: a review of the literature. Psychiatry Research (Neuroimaging), 271: 142-153.

Rao, S., Lam, M. H., Wing, Y. K., Yim, L. C., Chu, W. C., Yeung, V.S ., \& Waye, M. M. (2015). Beneficial effect of phosphatidylcholine supplementation in alleviation of hypomania and insomnia in a Chinese bipolar hypomanic boy and a possible explanation to the effect at the genetic level. Springerplus, 4: 235.

Shurtleff, W., \& Aoyagi, A. (2016). History of Lecithin and Phospholipids (1850 to 2016): Extensively Annotated Bibliography and Sourcebook, Including Phosphatides and Liposomes. Lafayette, CA: Soyinfo Center.

Smith, J., \& Hong-Shum, L., (eds.) (2011). Food Additives Data Book (2 ${ }^{\text {nd }}$ ed.). Chichester, West Sussex: Wiley-Blackwell.

Stoll, A. L., Sachs, G. S., Cohen, B. M., Lafer, B., Christensen, J. D, \& Renshaw, P. F. (1996). Choline in the treatment of rapid-cycling bipolar disorder: clinical and neurochemical findings in lithium-treated patients. Biological Psychiatry, 40(5): 382-388.

Su, W. J., Zhang, T., Jiang, C. L., \& Wang, W. (2018). Clemastine Alleviates Depressive-Like Behavior Through Reversing the Imbalance of Microglia-Related Pro-inflammatory State in Mouse Hippocampus. Front in Cellular Neuroscience, 12: 412. 
Szuhaj, B. F. (ed.) (1989). Lecithins: Sources, Manufacture \& Uses. Illinois: The American Oil Chemist's Society.

Tops, M., Boksem, M. A. S., Luu, P., Tucker, D. M. (2010). Brain substrates of behavioral programs associated with self-regulation. Frontiers in Psychology, 1: 152.

Tsoukalas, I. (2012). The origin of REM sleep: A hypothesis. Dreaming, 22 (4): 253-283.

Ulus, I. H., Millington, W. R., Buyukuysal, R. I., \& Kiran, B. K. (1988). Choline as an agonist: determination of its agonist potency on cholinergic receptors. Biochemical Pharmacology, 37: 2747-2755.

van Enkhuizen, J., Janowsky, D.S., Olivier, B., Minassian,A., Perry, W., Young, J. W., \& Geyer, M. A. (2015). The catecholaminergic-cholinergic balance hypothesis of bipolar disorder revisited. European Journal of Pharmacology, 753:114-126.

van Hoogevest, P., \& Wendel, A. (2014). The use of natural and synthetic phospholipids as pharmaceutical excipients. European Journal of Lipid Science and Technology, 116 (9): 1088-1107.

Vogel, G. W., Vogel, F., McAbee, R. S., \& Thurmond A. J. (1980). Improvement of depression by REM sleep deprivation. New findings and a theory. Archives of General Psychiatry, 37 (3): 247-253.

Wood, J. L., \& Allison, R. G. (1982). Effects of consumption of choline and lecithin on neurological and cardiovascular systems. Federation Proceedings, 41 (14): 3015-3021.

Wurtman, R. J., Cansev, M., \& Ulus, I. H. (2009). Choline and its products acetylcholine and phosphatidylcholine. In Lajtha, A., Tettamanti, G., \& Goracci, G. (eds.), Handbook of Neurochemistry and Molecular Neurobiology, pp. 443-501. Boston, MA: Springer.

Yildiz-Yesiloglu, A., \& Ankerst, D. P. (2006). Review of $1 \mathrm{H}$ magnetic resonance spectroscopy findings in major depressive disorder: a meta-analysis. Psychiatry Research, 147 (1): 1-25.

Xu, S., Peng, D., Jin, Z., Liu, H., \& Yang, J. (2005). Personality and neurochemicals in the human brain: A preliminary study using ${ }^{1} \mathrm{H}$ MRS. Chinese Science Bulletin, 50 (20): 23182322.

Zeisel, S. H., \& da Costa, K. A. (2009). Choline: an essential nutrient for public health. Nutrition Reviews, 67(11): 615-623. 


\begin{abstract}
${ }^{1}$ In the taxonomy of the European Food Safety Authority lecithin is given the codename E322.
2 There are other areas, as well, where a 'cholinergic loading' may be taking place. Lecithin is, for example, a common excipient in pharmaceutical formulations (van Hoogevest, \& Wendel, 2014). Several medical conditions are treated with drugs that enhance the workings of the cholinergic system of the brain; for example, acetylcholinesterase inhibitors, acetylcholine precursors or cholinomimetics in the case of Alzheimer's disease or myasthenia gravis. These practices, too, raise the specter of inadvertently causing depression in sensitive individuals, and this irrespective of their medical efficacy in treating the target condition. This specter is the more disconcerting as these diseases seem to be comorbid with depression (Kulaksizoglu, 2007; Aznar \& Knudsen, 2011). In support of this conjecture one recent study showed that decreased levels of acetylcholinesterase, the enzyme that breaks down excessive levels of acetylcholine, may be a cause of depression (Mineur et al., 2013).
\end{abstract}

${ }^{3}$ What I am alluding to is that the prevailing theory of the pathogenesis of depression - that depression is caused by a lack of serotonergic activity in the brain - has been seriously questioned in recent years (Fournier et al., 2010; Kirsch et al., 2010; Greenberg, 2010; Cipriani et al., 2016). Although the debate over the use of modern antidepressants continues unabated within the scientific community, as well as the public sphere, most experts nowadays agree that they are not the simple solution to the problem of depression they once were thought to be (they are not "happy pills"). Their therapeutic effect size is actually quite small and barely useful from a clinical perspective. Therefore, differing interpretations notwithstanding, new and better therapies for depression are sorely needed.

${ }^{4}$ The richest source of lecithin, by a wide margin, is egg yolk and, of course, I am not suggesting that it should be banned, although individuals prone to depression should be informed of the potential value of limiting its consumption.

${ }^{5}$ This is the so-called Hordaland Health Study, a population-based study, which found that those with the lowest plasma choline levels had significantly higher anxiety. 